\title{
Ceramic Breeder Pebble Bed Packing Stability under Cyclic Loads
}

\author{
Chunbo (Sam) Zhang ${ }^{\mathrm{a}}$, Alice Ying ${ }^{\mathrm{a}}$, Mohamed A. Abdou ${ }^{\mathrm{a}}$, Yi-Hyun Park ${ }^{\mathrm{b}}$ \\ ${ }^{a}$ Fusion Science and Technology Center, University of California, Los Angeles, CA 90095-1597, USA \\ ${ }^{b}$ National Fusion Research Institute, Daejeon, Republic of Korea
}

\begin{abstract}
Considering the optimization of blanket performance, it is desired that the bed morphology and packing state during reactor operation are stable and predictable. Both experimental and numerical work are performed to explore the stability of pebble beds, in particular under pulsed loading conditions. Uniaxial compaction tests have been performed for both KIT's $\mathrm{Li}_{4} \mathrm{SiO}_{4}$ and NFRI's $\mathrm{Li}_{2} \mathrm{TiO}_{3}$ pebble beds at elevated temperatures (up to $750^{\circ} \mathrm{C}$ ) under cyclic loads (up to $6 \mathrm{MPa}$ ). The obtained data shows the stress-strain loop initially moves towards the larger strain and nearly saturates after a certain number of cyclic loading cycles. The characterized FEM CAP material models for a $\mathrm{Li}_{4} \mathrm{SiO}_{4}$ pebble bed with an edge-on configuration are used to simulate the thermomechanical behavior of pebble bed under ITER pulsed operations. Simulation results have shown the cyclic variation of temperature/stress/strain/gap and also the same saturation trend with experiments under cyclic loads. Therefore, it is feasible for pebble bed to maintain its packing stability during operation when disregarding pebbles' breakage and irradiation.
\end{abstract}

Keywords: Packing stability, Ceramic breeder, Pebble bed, Cyclic loads

\section{Introduction}

Previous research on ceramic breeder pebble beds has revealed that thermally induced stress can cause packing changes and volume reduction of pebble beds, and thereafter allow pebble bed/wall separation [1-4]. Gan and Kamlah reported that gap formation is found at the interface of the FW in the middle sub-cell of the ceramic pebble layer, and the widths of the gaps are mainly in the range of $0.25-0.38 \mathrm{~mm}$ [3]. A deteriorated pebble bed/wall contact due to bed packing change may result in a significant decrease of heat transfer between pebble bed and wall, and increased temperatures in regions of the pebble bed [4].

However, very little work on the packing stability of pebble beds is available. Therefore, both experimental and numerical studies are performed to explore the packing stability for pebble beds, in particular under ITER-like pulsed operating conditions. This preliminary work identifies the stable regimes of pebble bed's packing with respect to operating temperature and compressive stress levels when ignoring the effects of pebbles' breakage and irradiation.

\section{Uniaxial compaction tests}

Since ITER operating condition has a pattern of pulsed plasma-on/-off, the pebble bed mechanical behavior has been experimentally explored as a function of uniaxial loading-unloading cycles. Cyclic uniaxial compaction tests are performed on both KIT's $\mathrm{Li}_{4} \mathrm{SiO}_{4}$ $(\mathrm{d}=0.25-0.6 \mathrm{~mm} ; 3 \%$ porosity; $61 \%$ P.F. $)$ and NFRI's $\mathrm{Li}_{2} \mathrm{TiO}_{3}(\mathrm{~d}=1.0 \mathrm{~mm} ; 10 \%$ porosity; $63 \%$ P.F.) pebble beds at elevated temperatures (up to $750^{\circ} \mathrm{C}$ ) under cyclic loads (up to 6MPa). The initial height of pebble bed is about $15 \mathrm{~mm}$. The axial stress/strain loops have been obtained and analyzed in details.

\subsection{Experimental setup}

UCLA's facility, shown in Fig. 1, employs a uniaxial/creep test stand (Zwick, Kappa 50 DS) and 3zone furnace (Max. $1200^{\circ} \mathrm{C}$ ) for pebble bed mechanical testing. A $50 \mathrm{kN}$ load cell is used for force measurement. A high-temperature LVDT sensor (Max. $230^{\circ} \mathrm{C}$ operation temperature) is used to measure the sample region deformation. To eliminate the error from piston's thermal expansion, the LVDT sensor and probe are mounted at the cup containing the pebble bed and bottom of the top piston. Pebbles are packed in a cup with $46.5 \mathrm{~mm}$ internal diameter, which sits on the lower piston and are compressed/decompressed by the upper piston with a constant rate of $1 \mathrm{MPa} / \mathrm{min}$. Both the cup and pistons are made of Inconel 718 due to its excellent mechanical strength at high temperatures. Thermocouples are placed underneath the cup and on the lower piston to monitor temperature profile and distribution. A quartz tube is sealed on the top and bottom pistons to provide a vacuum environment.

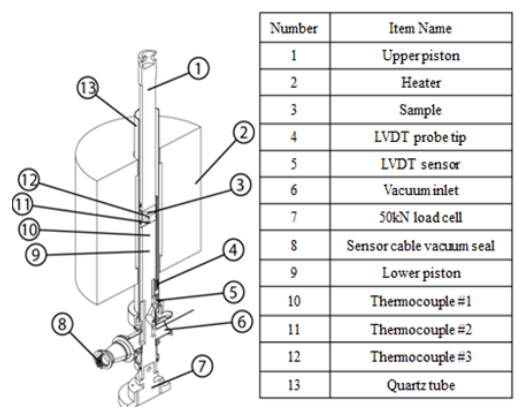

Fig. 1. Diagram of UCLA's uniaxial compaction/creep testing facility.

author's email: chunbozhang@fusion.ucla.edu 


\subsection{Experimental results}

Fig. 2 illustrates the typical pebble bed stress-strain behavior under cyclic uniaxial compressive loads. The axial strain value represents the permanent volume reduction of pebble bed when the unloading process is completed. Major volume reduction is generated during the initial few cycles, e.g. $2.5 \%$ for the first 2 cycles at $750^{\circ} \mathrm{C} / 6 \mathrm{MPa}$, which is attributed to pebble rearrangements. Subsequent cycles continue to result in bed volume reduction with smaller increments, e.g. only $0.5 \%$ more for the next 10 cycles combined. For the test at $550^{\circ} \mathrm{C} / 6 \mathrm{MPa}$, pebble bed has a smaller volume reduction of $2.0 \%$ after the $2^{\text {nd }}$ cycle and $0.4 \%$ more for the rest of 10 cycles, shown in Fig. 3. Since pebbles' creep has been observed at $750^{\circ} \mathrm{C}$, the bed volume reduction during these subsequence cycles may be dominated by creep. Under the cyclic stress of $6 \mathrm{MPa}$, the bed volume continues to decrease after 12 cycles.

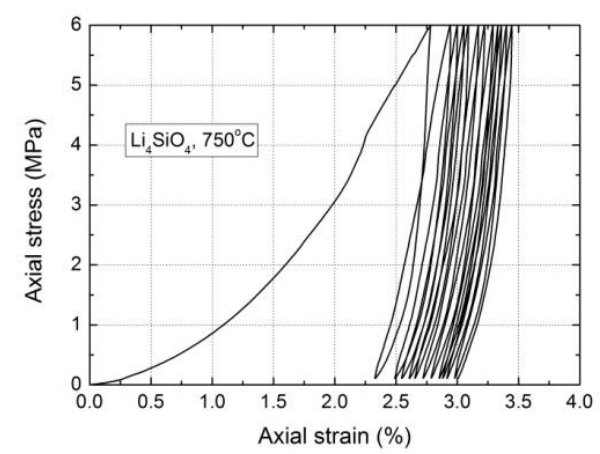

Fig. 2. Axial stress-strain loops of $\mathrm{Li}_{4} \mathrm{SiO}_{4}$ pebble bed at $750^{\circ} \mathrm{C}, 6 \mathrm{MPa}$ and 12 cycles.



Fig. 3. The volume reduction of $\mathrm{Li}_{4} \mathrm{SiO}_{4}$ pebble bed varying with cycle number at $750 / 550^{\circ} \mathrm{C}$ and $6 \mathrm{MPa}$.

In Figs. 3 and 4 , the evolution of $\mathrm{Li}_{4} \mathrm{SiO}_{4}$ pebble bed volume reduction with cycle number has been plotted for different temperature/stress conditions. We observe that bed volume decreases fast in the beginning and tends to saturate afterwards with continuous cycles. The tests conducted under the conditions of $550 \& 750^{\circ} \mathrm{C} / 3 \mathrm{MPa}$ show that $\mathrm{Li}_{4} \mathrm{SiO}_{4}$ pebble bed volume becomes stable after $\sim 85$ cycles. When other conditions remain the same, higher stress and temperature generate both a larger reduction and increased rate of pebble bed volume reduction. Since pebbles have more tendencies to creep at higher temperature, more cycles are needed for pebble bed to reach its steady state, in which the bed's packing has almost no further change under the same cyclic loads. The maximum compressive load of the cycle also affects the cycle number required for steady-state, depending on temperature level. Generally speaking, neglecting the influence of creep (i.e. beds at temperatures less than $650^{\circ} \mathrm{C}$ ), higher pressure speeds up pebble arrangements and requires fewer cycles for bed volume reduction to saturate. However, higher pressure also causes more creep deformation of pebble beds for a higher temperature, i.e. $750^{\circ} \mathrm{C}$, which requires more cycles to saturate.

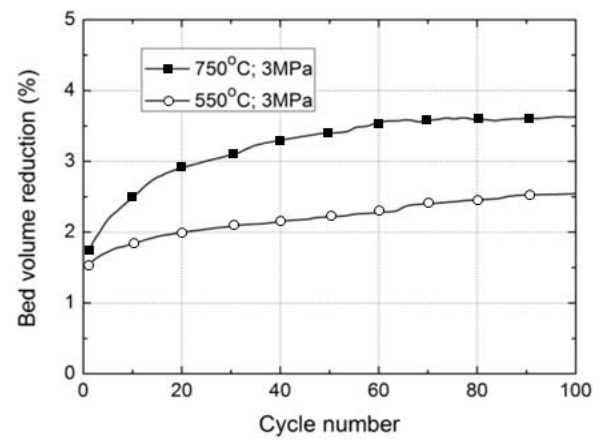

Fig. 4. The volume reduction of $\mathrm{Li}_{4} \mathrm{SiO}_{4}$ pebble bed varying with cycle number at $750 / 550^{\circ} \mathrm{C}$ and $3 \mathrm{MPa}$.

Similar tests were performed on $\mathrm{Li}_{2} \mathrm{TiO}_{3}$ pebble bed at an elevated pressure of $2 \mathrm{MPa}$ (3-step loadingunloading) and temperature of $750^{\circ} \mathrm{C}$ for 48 cycles, shown in Fig. 5 ( $1^{\text {st }}$ run). There is again very little bed volume reduction from one cycle to the next after the initial volume reduction is removed by compression. A volume reduction of $1.6 \%$ is resulted after the $2^{\text {nd }}$ cycle, and $0.9 \%$ more is found for the rest of 46 cycles. After the $1^{\text {st }}$ run, pebble bed total volume reduction was zeroed out and run through the same 3 -step loading-unloading sequence (Fig. 5, $2^{\text {nd }}$ run). It is observed that pebble bed shows a higher stiffness and much smaller packing change under the same testing condition.

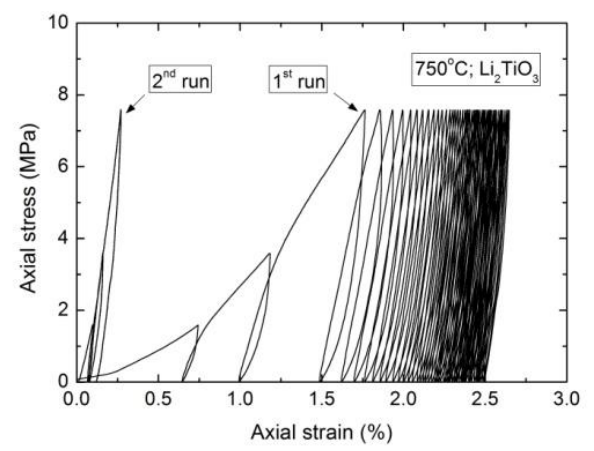

Fig. 5. Axial stress-strain loops of $\mathrm{Li}_{2} \mathrm{TiO}_{3}$ pebble bed at $750^{\circ} \mathrm{C}$.

In Fig. 6, the loading-unloading process begins with the routine steps of $0.5-1-2 \mathrm{MPa}$ and then is repeated for $1 \mathrm{MPa}$ cycles after 6 cycles at $2 \mathrm{MPa} / 550^{\circ} \mathrm{C}$. Evident from the data, after the first $2 \mathrm{MPa}$ compactions, the stressstrain curves for $1 \mathrm{MPa}$ cyclic tests follow nearly the 
same paths and show no bed volume change. In other words, after the cyclic loads at higher stress, pebble bed volume can be stabilized subsequently under the cyclic loads of lower stress state. This also implies that, with stress relaxed, pebble bed shows a pure non-linear elasticity with fully recovered deformation at the end of unloading. These results reveal that, within a similar magnitude of loading, a sort of steady-state compression cycle can be expected once the initial volume reduction is removed from a bed. Therefore, pebble bed thermomechanical behavior, including its packing variation, can be predicted and controlled when the initial packing of pebble bed is close to the stabilized condition identified by experiments.

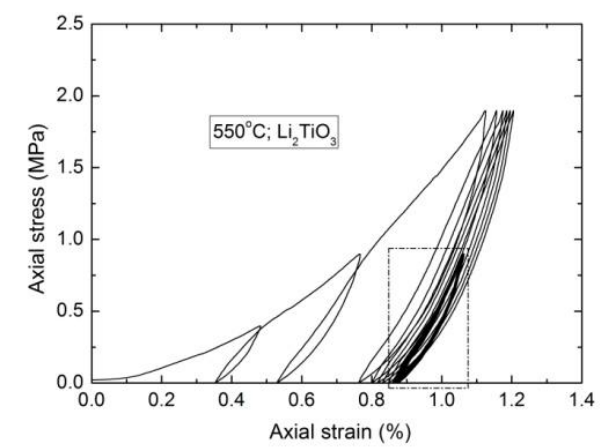

Fig. 6. Axial stress-strain loops of $\mathrm{Li}_{2} \mathrm{TiO}_{3}$ pebble bed at $550^{\circ} \mathrm{C}$.

Although preliminary experimental data have shown the basic pebble bed responses to cyclic loads, including the trend of bed volume reduction, existence of bed volume saturation and influences of temperature and pressure, systematic and comprehensive experimental work is necessary to further explore the trend and saturation of pebble bed volume within the temperature/pressure range during reactor operation, which provides the database for the study of pebbles' filling optimization and pebble bed's packing prediction/control.

\section{FEM simulation}

Previous results reveal the pebble bed responses to cyclic mechanical loads at elevated temperatures. To study the thermomechanical behavior of pebble beds in an edge-on configuration under ITER pulsed operations, FEM CAP models using ANSYS platform [5] have been developed, with material constitutive equations for a $\mathrm{Li}_{4} \mathrm{SiO}_{4}$ pebble bed. The FEM modeling details, such as governing equations and CAP model validation, can be found in Ref. 6. Simulation results, including the cyclic variation of temperature/stress/strain/gap, are presented and analyzed to explore the pebble bed responses to cyclic thermal loads.

\subsection{FEM model}

FEM modeling geometry and boundary conditions are shown in Fig. 7. The geometry of HELICA mock-up is taken from Ref. 3. The pebble bed has a dimension of $238.5 \mathrm{~mm} \times 25.4 \mathrm{~mm}$. A fixed coolant bulk temperature $\left(300^{\circ} \mathrm{C}\right)$ boundary condition and convective heat transfer $\left(1500 \mathrm{~W} / \mathrm{m}^{2}-\mathrm{K}\right)$ for cooling channels are applied. The model includes a surface heat flux $\left(0.5 \mathrm{MW} / \mathrm{m}^{2}\right)$ on the first wall (FW) and volumetric heat flux exponentially decreasing along the radial direction. Pebble bed/wall thermomechanical interactions have been simulated by meshing their interface with contact elements. The plasma cycle follows the ITER operation condition, 400s plasma-on and 1400s plasma-off. The structural container works in its elastic regime. Temperaturedependent material properties of pebble bed, including the effective modulus, CTE and thermal conductivity, are considered in simulation. Influences of gravity, creep, irradiation and purge gas flow are not included.

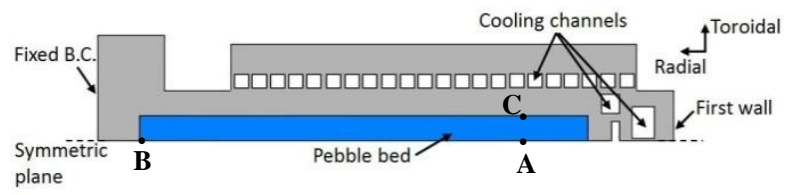

Fig. 7. FEM model geometry for the edge-on configuration.

\subsection{Simulation results}

Fig. 8 illustrates the temperature, stress and strain distributions of pebble bed at the end of the $1^{\text {st }}$ heating period $(\mathrm{t}=400 \mathrm{~s})$. A hot zone occurs inside pebble bed with the peak temperature of $797^{\circ} \mathrm{C}$. Due to pebble bed thermal expansion, compressive stress and strain concentrate inside pebble bed, and decreases away from its center. The peak radial stress and radial plastic strain are evaluated as $3.9 \mathrm{MPa}$ and $0.76 \%$, respectively. These concentrations are confined to a smaller region near the FW. Pebble bed/wall separation has been predicted and the gap distance distribution along the contact boundaries is shown in Fig. 9. Gap distance varies with contact location and the major gap in edge-on configuration is located on the short edge far away from the FW. At the end of cooling in the $1^{\text {st }}$ cycle $(t=1800 \mathrm{~s})$, a maximal radial gap distance of $0.65 \mathrm{~mm}$ is found.
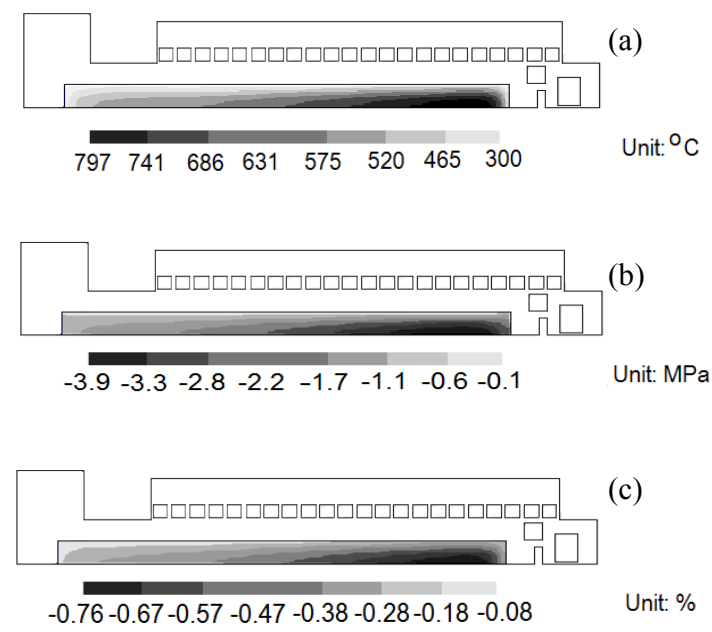

Fig. 8. Thermomechanical field distribution of $\mathrm{Li}_{4} \mathrm{SiO}_{4}$ pebble bed at the end of $1^{\text {st }}$ heating period $(\mathrm{t}=400 \mathrm{~s})$ : (a) temperature; (b) radial stress; (c) radial plastic strain. 


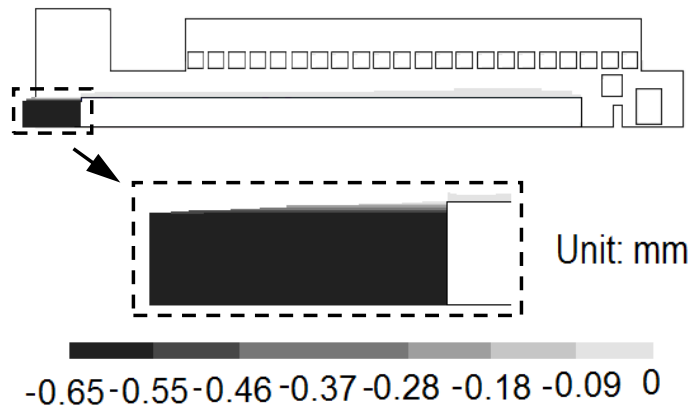

Fig. 9. Gap distance distribution at the end of the $1^{\text {st }}$ ITER cycle $(\mathrm{t}=1800 \mathrm{~s})$.

The location of predicted peak temperature in the bed is marked as Position A in Fig. 7. The cyclic evolution of thermomechanical values (temperature, stress and strain) at Position A are plotted in Figs. 10-12, respectively. Pebble bed temperature increases during heating period and thereafter drops to the coolant temperature at about 1000s, illustrated in Fig. 10. The same temperature evolution is repeated for the next thermal cycle. The thermal-induced stress keeps increasing during the entire heating period and quickly drops when the cooling period starts $(\mathrm{t}=400 \mathrm{~s})$. While the volumetric plastic strain remains constant after the heating period and starts to decrease when a gap of pebble bed/wall occurs. During the cooling period, pebble bed/wall separation is generated when pebble bed's dimension is smaller than the container at some particular time and position. The evolution of pebble bed/wall separation at Positions B and $\mathrm{C}$ are shown in Fig. 13, which starts at about 460s, and then the gap distance increases with time and saturates at about 1100 s.

With continuous plasma burn cycles, both toroidal and radial stresses among pebble bed have been relaxed due to the generation of more pebble bed volume reduction and will finally saturate after a certain number of cycles, shown in Fig. 11. The sources of stress relaxation come mainly from pebbles' plastic/creep deformation in FEM modeling. If creep effects were considered, stress could be relaxed faster and more cycles would be needed to reach a saturation state of pebble bed's packing.



Fig. 10. Cyclic temperature profile at Point A.

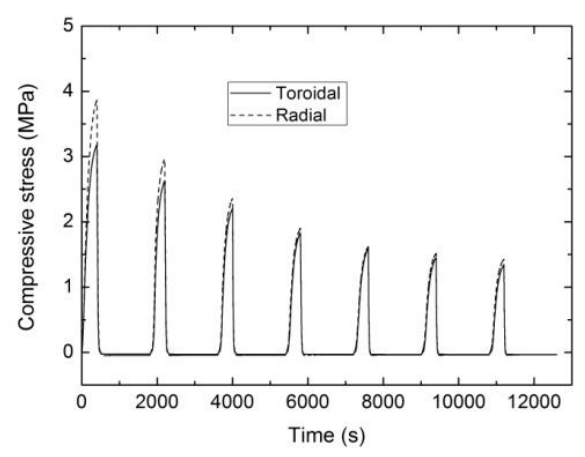

Fig. 11. Cyclic toroidal/radial compressive stress profiles at Point A.

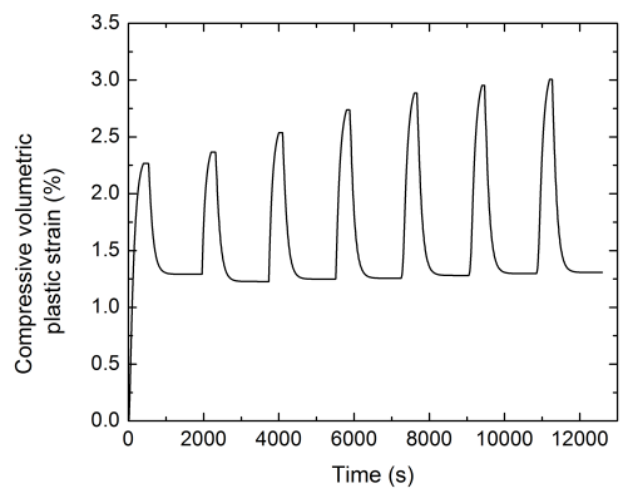

Fig. 12. Cyclic volumetric compressive plastic strain profile at Point A.

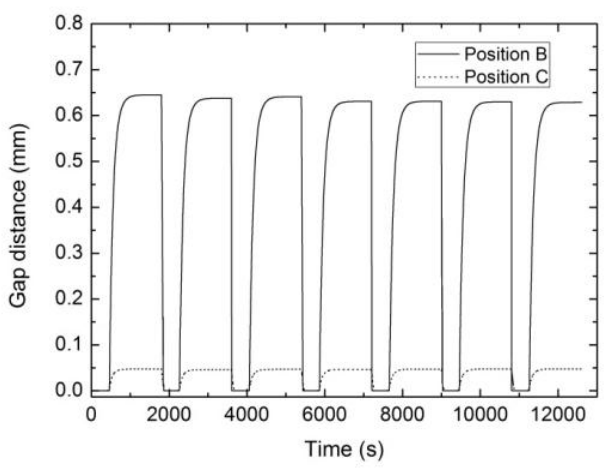

Fig. 13. Cyclic gap distance profiles at Points B and C.

\section{Discussions}

The significance of ceramic breeder pebble bed's packing stability is to ensure a stabilized heat removal from pebble bed to structural wall. The results presented above have shown the existence of pebble bed's packing saturation for different pebble materials and testing conditions, which indicates that it is possible for pebble bed to maintain its packing stability during operation when the proper blanket design and pebbles' filling procedure are applied.

Two factors, packing structure rearrangement and creep, are found to have the strongest influences on pebble bed's packing stability. Rearrangement is 
strongly dependent on the initial packing condition of pebble bed, which can result in a large bed volume reduction after the first few cycles. The reason is that the pebble filling by shaking only is not able to produce a packing condition sufficient to keep the bed's packing stable. Therefore, a method of applying cyclic mechanical loads, in addition shaking, during pebble filling is suggested, by which pebbles can be well packed and the packing stability of pebble bed can be improved significantly. However, the details of pre-compaction conditions, such as the load magnitude and/or the temperature, are yet to be defined.

The pebble bed/wall separation, due to the change of bed's packing, has been observed in FEM simulations of a breeder unit cell. Gap separation may result in a significant decrease of heat transfer between pebble bed and structural wall. To prevent such separation, the bed volume increase by thermal expansion needs to be larger than the sum of structural container volume increase by thermal expansion and pebble bed volume reduction itself during both heating and cooling periods.

\section{Conclusions}

Uniaxial compaction experiments and an FEM simulation are performed to study the responses of pebble beds to cyclic loads. Based on the obtained results and analysis, the following conclusions are drawn:

1) Major volume reduction of pebble bed is generated during the initial few cycles, which is mainly due to pebble rearrangements;

2) A stabilized packing of pebble bed has been observed in experiments with continuous cyclic loads; Higher stress and temperature generate both a larger bed volume reduction and increased rate of volume reduction within the studied parameter range;

3) After the cyclic loads at higher stress, pebble bed volume can be stabilized subsequently under the cyclic loads of lower stress state;

4) Applying mechanical loads is suggested when filling pebbles to improve the initial packing state;

5) It is feasible for pebble bed to maintain its packing stability during operation, disregarding the effects of pebbles' breakage and irradiation.

\section{Acknowledgments}

This work was supported by the U. S. Department of Energy Contract DE-FG03-ER52123. Ceramic breeder pebbles were provided by KIT and by Task Agreement between UCLA-NFRI for Cooperation on R\&D for Fusion Nuclear Science to Expedite the Realization of Magnetic Fusion Energy.

\section{References}

[1] J. Reimann, R.A. Pieritz and R. Rolli, Topology of compressed pebble beds, Fusion Engineering and Design 81 (2006) 653-658.

[2] A. Ying et al., Status of Ceramic Breeder Pebble Bed Thermo-mechanics R\&D and Impact on Breeder Material Mechanical Strength, Fusion Engineering and Design, 87 (2012) 1130-1137.

[3] Y. Gan and M. Kamlah, Thermo-mechanical analyses of HELICA and HEXCALIBER mock-ups, Journal of Nuclear Materials, 386-388 (2009) 1060-1064.

[4] Y. Gan and M. Kamlah, Thermo-mechanical modelling of pebble bed-wall interfaces, Fusion Engineering and Design, 85 (1) (2010) 24-32.

[5] Mechanical APDL Theory Reference, ANSYS release 14.0, 2011.

[6] C. Zhang, A. Ying and M. Abdou, FEM modeling of pebble bed/structural wall separation, Fusion Science and Technology, 68 (3) 2015. 